\title{
MARKET ANALYSIS OF MEDICINAL PRODUCTS FOR TREATMENT OF BENIGN PROSTATIC HYPERPLASIA (BPH)
}

\author{
Steliana Yordanova ${ }^{1}$, Galina Petrova ${ }^{2}$, Jivko Kolev ${ }^{3}$, Todorka Kostadinova ${ }^{2}$ \\ ${ }^{1}$ Master of Pharmaceutical management, Medical University of Varna, Bulgaria \\ ${ }^{2}$ Department of Economics and Healthcare Management, Faculty of Public Health, \\ Medical University of Varna, Bulgaria \\ ${ }^{3}$ Department of Pharmaceutical Sciences and Pharmaceutical Management, \\ Faculty of Pharmacy, Medical University of Varna, Bulgaria
}

\begin{abstract}
The aim of this article is to analyse the market of prescription medications for benign prostatic hyperplasia (BPH). The research is based mainly on IMS Health data on prescription medicines for BPH. Factors influencing the market of BPH-related medicines are prices, changes in the attitudes of doctors and the process of reimbursement. The market of products for treatment of BPH in Bulgaria has registered a steady growth for the past two years. Almost all participants in the market show development in number of sold packages/boxes.
\end{abstract}

Keywords: analysis, market, treatment, products, benign prostatic hyperplasia

\section{INTRODUCTION}

The pharmaceutical industry creates and develops new or approved therapeutic agents and consumables, aiming to meet the unsatisfied needs of their customers. It is one of the largest and most dynamically developing industries. 3.2 billion euro (IMS Health) were spent on healthcare in Bulgaria in 2013. Considering the past 2-3 years we can speak of relative stability or changes with slight influence. In Bulgaria treatment of BPH with medications made its way in 1995 and in the first years the market bare-

Address for correspondence:

Galina Petrova,

Faculty of Public Health,

Department of Economics and Healthcare Management

Medical University of Varna

55 Marin Drinov Str.

9002 Varna, Bulgaria

e-mail:gal_rumenova@abv.bg

Received: April 01, 2015

Accepted: May 27, 2015 ly reached 200000 BGN per year. During that period only original Tamsulosin was marketed (from the end of 1997), Doxazisin (from the middle of 1997), Finasterid (from the beginning of 1995), hormonal therapy and 1-2 phytotherapy products. Prices of medicines were comparable in the absence of or very low reimbursements then provided by municipalities. Broadly speaking, the reasons for the low market share at that time were both doctors' attitudes and lack of experience, as well as the low level of patients' awareness. In the course of time and after the patents expired, lots of new original and generic medicines appeared on the market.

\section{MATERIALS AND METHODS}

Analysis of documents and published sources; comparative analysis of data on prescription medicines for benign prostatic hyperplasia from IMS Health. 
Steliana Yordanova, Galina Petrova, Jivko Kolev et al.

\section{RESULTS AND DISCUSSION}

A number of factors have an impact on the development of the pharmaceutical market in Bulgaria. They have been very dynamic for a particular period of time, which has challenged market development forecasts. A major competitor of treatment with medications has been the surgical approach, as according to many medical textbooks, TURP (transurethral resection of the prostate) has been a "gold standard" approach for $\mathrm{BPH}$. The changes in prices of medicines, as well as the changes in the attitudes of doctors, the prescribing practices, and the process of reimbursement also had an impact. With the launch of the reimbursement system in June 2000 and the TV commercials of phytotherapy products for the treatment of $\mathrm{BPH}$ the market changed drastically.

The main groups of medicines for the treatment of $\mathrm{BPH}$ are:

* Original Tamsulosin;

* Generic Tamsulosin;

* Other a-blockers (selective and non-selective, original and generic);

* 5 a-reductase Inhibitors;

* Combination Drugs;

* Phytotherapeutic products and food supplements.

The pharmaceutical companies marketing medicines for the treatment of $\mathrm{BPH}$ have different portfolios. Some of them offer two or more products. The largest group is the one of plant extracts from which only a small part is marketed by doctors, and the majority relies on advertising.

Each of the companies struggles for a market share and the maintaining of positions is primarily a matter of product price. This approach is typical for producers of generics and as a whole has a positive effect on the market since the majority of the patients are able to afford the treatment. Products with the active ingredient tamsulosin represent the largest market share of prescription products. They are the most numerous and competition is chiefly among themselves. Some of the manufacturers change product prices several times a year, thus producing a double effect: firstly, they reach the lowest price within their class and secondly, they become a point of reference for other Tamsulosins. No such tendency is observed for the group of the plant extracts.

The pharmaceutical market is extremely specific mostly because it is subject to serious regulations. Two are the basic market regulators - the National Health Insurance Fund and the Association of the Research-Based Pharmaceutical Manufacturers in Bulgaria (ARPharM) through the Code of Ethics. The first regulator determines the way and rules of reimbursement which have been seriously changed in the course of the years. That makes correct forecasting of the market development of a particular product very difficult.

Initially the reimbursement for BPH medicines was $25 \%$ of its own price i.e. each product was its own point of reference. Later it has been changed to $50 \%$ of the price of the cheapest generic product which is highly unfavourable for medicines with higher price. The period for filing applications for reimbursement has also been changed - from no specific time period to twice a year and since June 2014 - once a year. This means that the manufacturer has to wait until the $1^{\text {st }}$ January to get a reimbursement. The second regulator, which concerns only brand-name companies, is the Association of the Research-Based Pharmaceutical Manufacturers in Bulgaria (ARPharM). Through annual changes in the Code of Ethics it constantly limits the activities of its members. The majority of the restrictions are in the right direction. This however, creates inequality between the brand-name and generic pharmaceutical companies and affects their relationships with clients who, on the other hand, do not distinguish between them.

Table 1. Market development of prescription products for treatment of BPH by number of packages/boxes and market

\begin{tabular}{|c|c|c|c|c|}
\hline Product/Year & 2012 & 2013 & 2012 & 2013 \\
\hline Total Market & 1259008 & 1469678 & Market Share & Market Share \\
\hline Original Tamsulosin 0,4 mg & 136828 & 172781 & $10.87 \%$ & $11.76 \%$ \\
\hline Generics & 437868 & 480118 & $34.78 \%$ & $32.67 \%$ \\
\hline
\end{tabular}

Source: IMS Health 
There is a huge diversity on the Bulgarian market of products for the treatment of $\mathrm{BPH}$, the prescription products being more than 20 and phytotherapy ones about the same number. Despite that the market is constantly growing and new products are being offered.

This analysis covers a period of two years -2012 and 2013, since in 2012 the price of the original Tamsulosin $0.4 \mathrm{mg}$ was reduced by $35 \%$ and it is pointless to include a longer past period. Part of the $a$-blockers (Doxazosin) are used for treatment of arterial hypertension but it is considered that the number of packages sold for that indication is a negligible amount, bearing in mind the rating of this class of medicines in the therapeutic approach towards this disease.

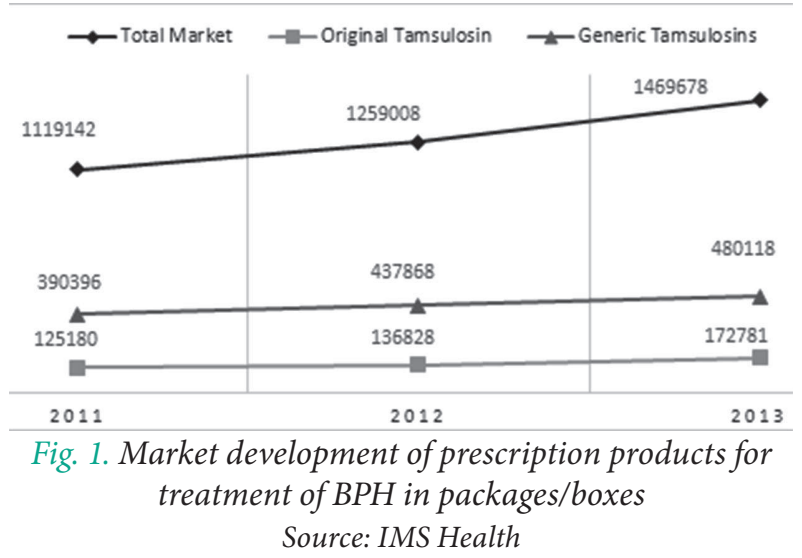

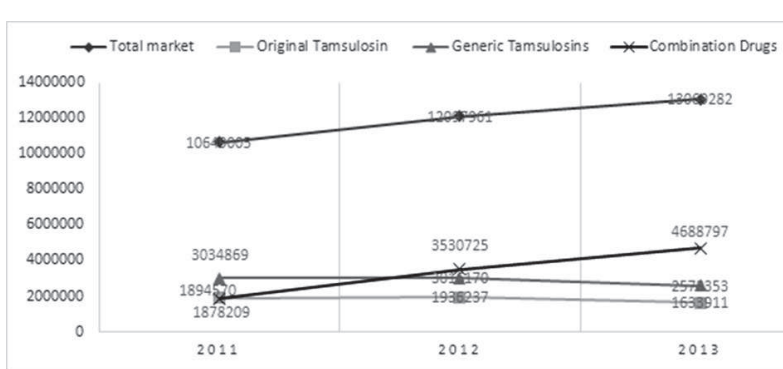

Fig. 2. Market development of prescription products for treatment of $B P H$ in money (Euro)

Source: IMS Health

In comparison with the prices of ethical pharmaceutical products for treatment of $\mathrm{BPH}$ we will review the dynamics of the market in the past 2 years in packages/boxes and money.

Figure 1 indicates that although the market of prescription products for the treatment of $\mathrm{BPH}$ is saturated, it continues to grow with a preference for lower-price generics.

Presented data shows market growth. Combination drugs are the key market driver. The reduction in the price of the majority of Tamsulosins as well as that of the original Tamsulosin $0.4 \mathrm{mg}$ leads to a reduction in their market share in terms of money. The increased sales in packages/boxes are smaller in percentages than the price reduction of original Tamsulosin $0.4 \mathrm{mg}$ in percentages which determines the decline in sales in terms of money. The data in-

Table 2.Development of the market of prescription products for treatment of BPH in money (Euro)/market share

\begin{tabular}{lcccc} 
Product|Year & 2012 & 2013 & 2012 & 2013 \\
Total Market & 12097961 & 13069282 & Market Share & Market Share \\
Original Tamsulosin & 1936237 & 1633911 & $16.00 \%$ & $12.50 \%$ \\
Generic Tamsulosins & 3016170 & 2578353 & $24.93 \%$ & $19.73 \%$ \\
Combination Drugs & 3530725 & 4688797 & $29.18 \%$ & $35.88 \%$ \\
\hline
\end{tabular}

Source: IMS Health

Table 3. Development of the market of prescription products for treatment of BPH in days of treatment (DOT)

$\begin{array}{lcc}\text { Product|Year } & 2012 & 2013 \\ \text { Total market } & 100 \% & 100 \% \\ \text { Original Tamsulosin } & 11.94 \% & 12.89 \% \\ \text { Generic Tamsulosins } & 36.33 \% & 32.96 \%\end{array}$

Source: IMS Health dicates that preferences are for the cheapest generics.

There is a clear tendency for shrinking of the market share in money of the original Tamsulosin $0.4 \mathrm{mg}$, the generic Tamsulosins and an increase in the market share of the combination drugs.

Table 3 shows a clearly expressed tendency towards reduction of the market share in terms of days of treatment for generic Tamsulosins. The tendency 
is for growth in the market share in terms of days of treatment with original Tamsulosin $0.4 \mathrm{mg}$.

\section{CONCLUSIONS}

Due to the specific nature of its production the pharmaceutical industry is one of the most regulated manufacturing activities in countries with developed market economy. This is the main reason why state authorities, namely the Ministry of Finance, the Ministry of Healthcare, the National Health Insurance Fund and municipalities play a determining role in the marketing of pharmaceutical products (the so called "institutional users").

The market of medicines for the treatment of $\mathrm{BPH}$ keeps growing. Almost all participants in the market show development in the number of sold packages/boxes - the increase for the original Tamsulosin $0.4 \mathrm{mg}$ is $38 \%$ which surpasses the development speed of the total market, which is $31 \%$.

The market of medicinal products for the treatment of BPH is not an exception from the general pharmaceutical market. Although not so dynamic as it was a few years ago, it continues to provoke interest and new manufactures and/or molecules (mainly generic ones) keep appearing. The market analysis shows that Tamsulosin $0.4 \mathrm{mg}$ is still the market leader for $\mathrm{BPH}$ treatment.

\section{REFERENCES}

1. Gacci M, Corona G, Salvi M et al. A systematic review and meta-analysis on the use of phosphodiesterase 5 inhibitors alone or in combination with a-blockers for lower urinary tract symptoms due to benign prostatic hyperplasia. Eur. Urol. 2012 May; 61(5):994-1003.

2. Leveillee R. Patel V. Prostate hyperplasia, benign. 2010. http://emedicine.medscape.com

3. Wilt T.et N'Dow J. Benign prostate hyperplasia Part 1 - Diagnosis. BMJ. 2008;336: 146-150.

4. http://www.astellas.eu

5. http:// www.consumerreports.org

6. http://www.imshealth.com/portal/site/ imshealth?CURRENT_LOCALE=bg_bg

7. http://www.medinfo.bg 